\title{
Positive correlation between regional emergency medical resources and mortality in severely injured patients: results from the Korean National Hospital Discharge In-depth Survey
}

\author{
Hyo Jung Lee, RN, $\mathrm{MPH}^{*}{ }^{\dagger}$; Yeong Jun Ju* ${ }^{\dagger}$; Eun-Cheol Park, MD, PhD*
}

\section{ABSTRACT}

Objectives: In South Korea, injury is a public health problem due to its high incidence and high mortality. To improve emergency medical systems, the government announced plans to increase the emergency medical resources for each region. This study investigated the association between regional emergency medical resources and mortality during hospitalization in severely injured inpatients.

Methods: To analyse mortality for severely injured inpatients, we used the Korean National Hospital Discharge In-depth Survey data, consisting of 18,621 hospitalizations from 20052012. Generalized estimating equations were analysed to examine the association between mortality during hospitalization and both individual and regional variables.

Results: Mortality during hospitalization occurred in 913 (4.9\%) cases. Patients in regions with a higher number of emergency departments (odds ratio $[\mathrm{OR}]=0.94,95 \%$ confidence interval [Cl]: 0.91-0.98), a higher number of ambulances (OR $=0.99$, $95 \% \mathrm{Cl}: 0.98-0.99)$, and a higher number of registered nurses per emergency department (OR $=0.88,95 \% \mathrm{Cl}$ : $0.83-0.94$ ) had a lower risk of mortality during hospitalization.

Conclusions: Our findings suggest that regional emergency medical resources are associated with a lower risk of mortality during hospitalization in severely injured patients. Thus, health care policymakers need to determine the proper distribution of emergency medical resources for each region and the function of emergency departments to provide a superior quality of emergency medical services to patients.

\section{RÉSUMÉ}

Objectifs: Les blessures représentent, en Corée du Sud, un problème de santé publique en raison de leur fréquence élevée et de leur mortalité importante. Afin d'améliorer les systèmes médicaux d'urgence, le gouvernement a annoncé des plans visant à accroître la disponibilité des ressources médicales d'urgence dans chaque région du pays.
L'étude avait donc pour but d'examiner l'association entre les ressources médicales d'urgence en région et la mortalité en cours d'hospitalisation chez les blessés graves.

Méthode: Afin d'analyser la mortalité chez les blessés graves hospitalisés, les auteurs ont utilisé des données provenant de la Korean National Hospital Discharge In-depth Survey, portant sur 18621 patients hospitalisés, de 2005 à 2012. L'équipe de recherche a procédé à l'analyse d'équations d'estimation généralisées afin d'examiner l'association entre la mortalité en cours d'hospitalisation et les variables tant individuelles que régionales.

Résultats: II y a eu décès en cours d'hospitalisation dans 913 cas $(4,9 \%)$. Les patients traités dans les régions bien dotées en services des urgences (SU) (risque relatif approché [RRA] = 0,94; intervalle de confiance [IC] à $95 \%: 0,91-0,98)$, en ambulances (RRA =0,99; IC à $95 \%: 0,98-0,99$ ) et en personnel infirmier par SU (RRA =0,88; IC à $95 \%$ : 0,83-0,94) connaissaient un risque réduit de mortalité en cours d'hospitalisation. Conclusions: D'après les constatations de l'étude, la disponibilité des ressources médicales d'urgence en région est associée à une diminution du risque de mortalité en cours $\mathrm{d}^{\prime}$ hospitalisation chez les blessés graves. Aussi les décideurs de politiques en matière de soins de santé doivent-ils déterminer une distribution appropriée des ressources médicales d'urgence dans chaque région et tenir compte de la fonction des SU afin d'offrir aux patients des services médicaux d'urgence de qualité.

Keywords: emergency medical care system, mortality, regional emergency medical resources, trauma

\section{INTRODUCTION}

Injury is a public health problem in South Korea due to its high incidence and mortality. In 2013, a statistical

From the ${ }^{*}$ Institute of Health Services Research; †Department of Public Health, and $\ddagger$ Department of Preventive Medicine, Yonsei University, Seoul, Republic of Korea.

Correspondence to: Dr. Eun-Cheol Park, Department of Preventive Medicine, Institute of Health Services Research, Yonsei University, College of Medicine, 50 Yonsei-ro, Seodaemun-gu, Seoul 120-75-2, Republic of Korea; Email: ecpark@yuhs.ac

(C) Canadian Association of Emergency Physicians $\quad$ CJEM 2017;19(6):450-458

DOI 10.1017/cem.2016.402 
report on causes of death indicated that the rate of mortality due to injury was 61.3 per 100,000 people. ${ }^{1}$ Injury is the third leading cause of death, and its mortality rate is higher than average in Organization for Economic Cooperation and Development (OECD) countries. $^{2}$ In addition, preventable mortality in trauma patients is $35.2 \%$, which is very high compared to the United States or Japan, whose preventable mortality rates in trauma patients range from $10 \%$ to $15 \%{ }^{3,4}$ Because death caused by injury occurs mostly when one is of a working age, there are costs associated with such social losses. ${ }^{5}$

In South Korea, emergency medical institutions are divided into three types: regional emergency medical centres, local emergency medical centres, and local emergency medical institutions; these are categorized based on the facilities, personnel, and equipment for each region (see Supplementary Material). The purpose of introducing such a classification system is to provide effective emergency medical services, depending on the severity of injury. ${ }^{6}$ There are 21 regional emergency medical centres, 199 local emergency medical centres, and 293 local emergency medical institutions. ${ }^{7}$ However, this system does not seem to be working sufficiently. Although emergency medical centres are required to meet certain standards, the Ministry of Health \& Welfare reported that $6 \%$ of regional emergency medical centres, $13 \%$ of local emergency medical centres, and $53 \%$ of local emergency medical institutions do not meet the minimal personnel requirements. ${ }^{8}$ In addition, even patients with mild complaints have been unduly concentrated in regional emergency medical centres, because they are likely to think that the quality of care is higher in regional emergency medical centres than in other emergency centres. ${ }^{9}$ This overcrowding condition makes it difficult to provide adequate care to patients arriving in the emergency department (ED). As a result, delays in the diagnosis and treatment of severely injured patients occur, which can adversely affect patient outcome. ${ }^{10}$

Under this current emergency medical system, the government announced that the number of regional emergency medical centres would need to double, and improvements would need to be made to the facilities, equipment, and personnel criteria of each regional emergency medical centre in order to actively accept randomly occurring severe emergency patients and offer the timely emergency medical services required in order to reduce the mortality rate of severely injured patients. ${ }^{11}$ There have been many studies on the relationship between regional medical resources and health outcomes. Several studies have investigated the relationship between the number of surgeons and the mortality rate, finding that a greater number of surgeons correlates with lower mortality. ${ }^{12,13}$ Others showed that an organized or regionalized trauma system improved the health outcomes of injured patients. ${ }^{14-17}$ In South Korea, one study estimated that areas with a high deprivation index and rural areas had high trauma mortality rates. ${ }^{18}$ Similarly, a study reported that areas that are vulnerable to socioeconomic inequality and thus lack health care services have high trauma mortality rates. ${ }^{19}$ However, studies on the distribution of emergency medical resources and health outcome are lacking in South Korea.

Therefore, this study investigated the association between regional emergency medical resources and mortality in severely injured trauma inpatients to ensure that the suggestions for improvement are effective. In this study, the number of EDs and ambulances for each effective population unit was considered to determine the ease of ED accessibility for emergency patients, and the numbers of registered nurses (RNs), emergency medicine specialists, and total specialists were also considered to investigate their effects on ED-to-treatment time and quality of treatment after arriving in the ED.

\section{MATERIALS AND METHODS}

\section{Study population}

This study used Korean National Hospital Discharge In-depth Survey data released by the Korea Centers for Disease Control and Prevention (KCDC) from 2005 to 2012. This survey included sampling results from hospitals and patients. In other words, after sampling hospitals with over 100 hospital beds based on the criteria of number of beds and region, discharged patients from the sampled hospitals were also sampled by discharge date, sex, and age. Although the total number of hospitals with more than 100 beds differed each year from 2005 to 2012, they were not greatly different. Thus, these survey data were built on the medical records of patients who visited 144 to 170 hospitals. Only inpatients were included, and those who stayed only in the ED were excluded.

The subjects of this study were patients hospitalized after a visit to the ED due to severe injury. We defined severe trauma disorders using the International 
Classification of Diseases (ICD-10) groupings. The Central Emergency Center reported the primary diagnosis of severe trauma disorder based on an ICDbased injury severity score (ICISS) of $\geq 0.9$ : S049, S06, S061, S065 S069, S158, S199, S260, S279, S317, S352, S353, S355, S357, S359, S367, S750, T029, T179, T791, and T794. ${ }^{20}$ A total of 18,621 inpatients with the previous primary diagnoses were included in the analysis. A selection flowchart of the study population is shown in Figure 1. This study used encrypted data from which personal information could not be identified. Therefore, ethics approval and informed consent were not required for this study.

\section{Measures}

We used mortality during hospitalization as the outcome measure in severely injured trauma inpatients. Those who were discharged due to death were included; however, those who stayed in the ED only or died on scene were not included due to data limitations. The primary variables of interest related to mortality during hospitalization were the regional emergency medical resources. Regional variables were based on indicators of the Emergency Medical Statistics conducted by the National Emergency Medical Center and on those of the annual surveys conducted by Statistics Korea, as follows: number of EDs per 1,000,000 people, number of ambulances per 100,000 people, number of RNs per ED, number of emergency medicine specialists per ED, number of total specialists per ED, rate of taking less than 1 hour to arrive at the ED after onset, gross regional domestic product (GRDP), and population density. ${ }^{21,22}$ The regional indicators were variables representing the 16 regions of Korea. GRDP as a value-added variable on the production side was used as an indicator to measure the value of economic activities in each region.

For the analysis of the relationship between regional emergency medical resources and mortality during hospitalization, we adjusted for individual characteristics. Individual characteristics included age, sex, length of stay, Charlson Comorbidity Index (CCI), type of

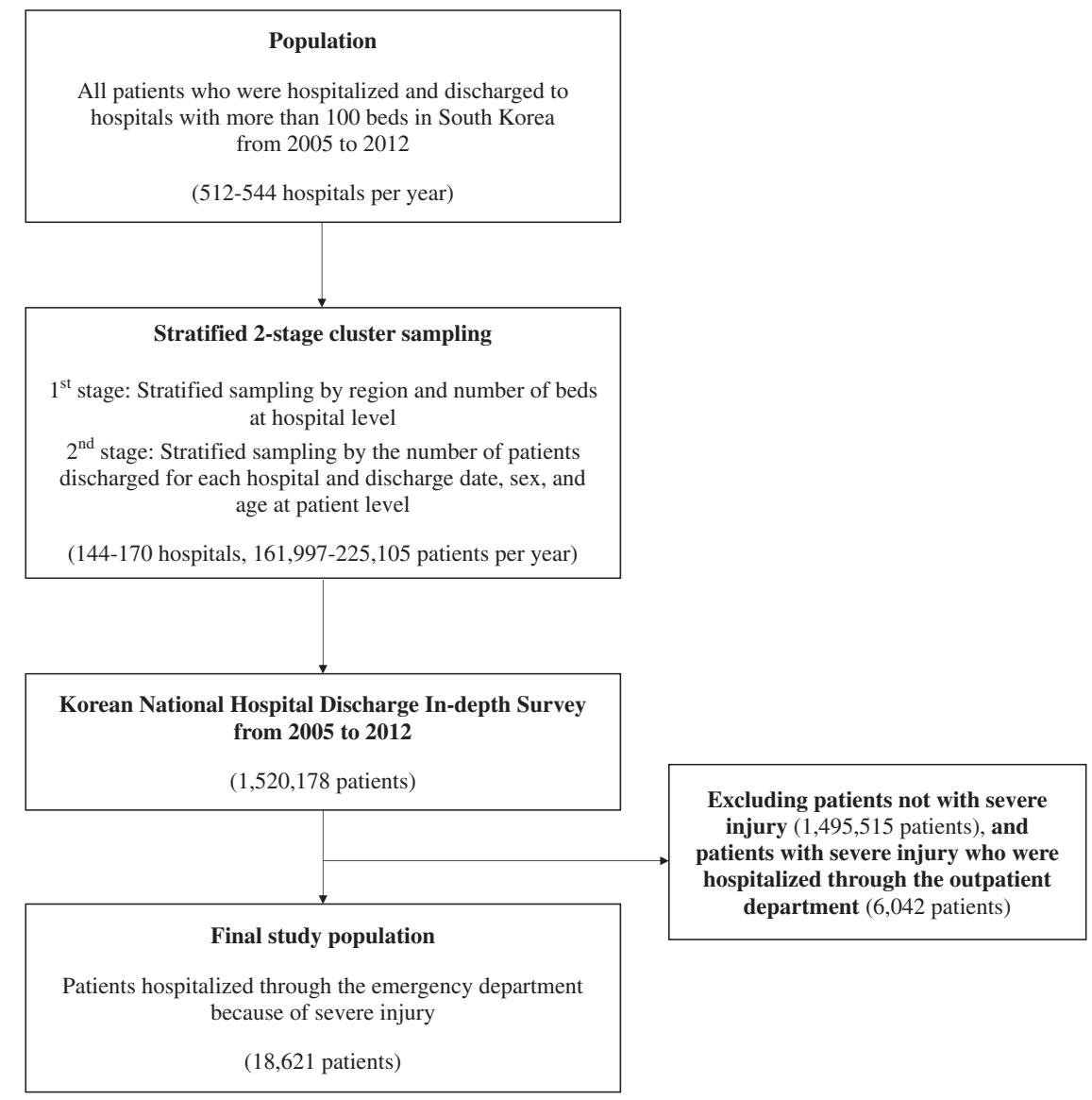

Figure 1. Selection flowchart of study population. 
insurance coverage, intention of injury, main injury location, type of severe injury, number of hospital beds, and year of hospitalization. The CCI was used to account for the effects of comorbid disorders or diseases. Main injury location was categorized as head or neck or other, and type of severe injury was categorized as multiple or single injury. If patients had more than two diagnoses of severe trauma, they were categorized as multiple-injury patients. Otherwise, they were categorized as single-injury patients.

\section{Statistical analysis}

We determined the distribution of each categorical variable by examining frequencies and percentages, and we performed $\chi^{2}$ tests to investigate any associations with mortality during hospitalization. These analyses were performed for both individual characteristics and regional characteristics. Student's $t$-test was performed for continuous variables. In addition, generalized estimating equations (GEEs), including both individual and regional characteristics, were used to examine the association of mortality during hospitalization with these characteristics. Subgroup analyses were also performed according to the type of severe injury. All statistical analyses were performed using SAS statistical software, version 9.3. All $p$ values calculated were two-sided and considered significant at $p<0.05$.

\section{RESULTS}

The data used in our study included 18,621 hospitalizations. Mortality during hospitalization occurred in 913 $(4.9 \%)$ cases. Table 1 shows the univariate associations between mortality during hospitalization and each independent variable, including regional emergency medical resources. Among the individual characteristics, death was more frequent in male inpatients than in female inpatients $(6.1 \%$ for males v. $3.1 \%$ for females). In addition, inpatients who died during hospitalization were older than those who did not. Treatment type and type of severe injury were associated with the frequency of mortality. Regarding regional characteristics, the average numbers of EDs, ambulances, and RNs per ED were lower when patients died during hospitalization. In contrast, the numbers of emergency medicine specialists and total specialists per ED were higher when patients died during hospitalization. High population densities had high mortality rates.
Table 2 shows the results of GEEs for mortality, considering both individual and regional characteristics. Female patients exhibited a lower risk of mortality during hospitalization than male patients $(\mathrm{OR}=0.63$, 95\% CI: 0.53-0.74). Older patients had a higher risk of mortality during hospitalization than younger patients $(\mathrm{OR}=1.02,95 \% \mathrm{CI}:$ 1.01-1.02). Analyses of CCI scores revealed that higher scores were associated with a greater risk of mortality during hospitalization $(\mathrm{OR}=$ 1.81, 95\% CI: 1.23-2.66). Multiple-injury patients had a higher risk of mortality during hospitalization than single-injury patients. The GEEs of regional characteristics showed that patients in regions with a higher number of EDs had a lower risk of mortality during hospitalization (OR $=0.94,95 \% \mathrm{CI}$ : 0.91-0.98). Similarly, a higher number of ambulances per 100,000 people was significantly associated with a lower risk of mortality (OR $=0.99,95 \%$ CI: $0.98-0.99)$. Patients in regions with a higher number of $\mathrm{RNs}$ per $\mathrm{ED}(\mathrm{OR}=$ $0.88,95 \%$ CI: $0.83-0.94)$ or a higher rate of taking less than 1 hour to arrive to the ED after onset $(\mathrm{OR}=0.10$, 95\% CI: 0.02-0.62) had a lower risk of mortality during hospitalization. Patients in regions with a higher population density had a higher risk of mortality $(\mathrm{OR}=1.04,95 \%$ CI: 1.00-1.07).

We also performed subgroup analyses according to the type of severe injury for trauma inpatients (Table 3 ). The numbers of EDs, RNs, and rate of taking less than 1 hour to arrive at the ED after onset were all significantly associated with mortality in single-injury patients. However, in multiple-injury patients, emergency medical resources were not associated with mortality during hospitalization.

\section{DISCUSSION}

Our findings suggest that the number of EDs per $1,000,000$ people, the number of ambulances per 100,000 people, the number of RNs per ED, and rate of taking less than 1 hour to arrive at the ED after onset had an inverse relationship with mortality. These results support several studies that reported that surviving a major injury was strongly associated with reaching definitive care (that is, a hospital that could provide optimal treatment) as quickly as possible. ${ }^{16,23,24}$

However, in this study, the number of emergency medicine specialists and total specialists per ED did not have a significant relationship with the mortality rate, unlike the results of previous studies. ${ }^{12,13,25}$ 


\begin{tabular}{|c|c|c|c|c|c|c|c|}
\hline \multirow[b]{2}{*}{ Variables } & \multicolumn{2}{|c|}{ Total } & \multicolumn{2}{|c|}{ Death } & \multicolumn{2}{|c|}{ Alive } & \multirow[b]{2}{*}{$p$-value } \\
\hline & $\mathrm{N} /$ mean & $(\%) / \pm S D$ & $\mathrm{~N} /$ mean & $(\%) / \pm S D$ & $\mathrm{~N} /$ mean & $(\%) / \pm S D$ & \\
\hline \multicolumn{8}{|l|}{ Individual characteristics } \\
\hline \multicolumn{8}{|l|}{ Sex } \\
\hline Male & 11,351 & $(61.0)$ & 687 & (6.1) & 10,664 & (94.0) & $<0.0001$ \\
\hline Female & 7270 & (39.0) & 226 & (3.1) & 7044 & (96.9) & \\
\hline Age & 44.8 & \pm 20.9 & 54.8 & \pm 20.4 & 44.3 & \pm 20.8 & $<0.0001$ \\
\hline \multicolumn{8}{|l|}{ Type of insurance coverage } \\
\hline $\mathrm{NHI}$ & 7307 & (39.2) & 447 & (2.4) & 6860 & (97.6) & $<0.0001$ \\
\hline Medical-aid & 765 & $(4.1)$ & 67 & (8.8) & 698 & (91.2) & \\
\hline Vehicle insurance & 10,549 & $(56.7)$ & 399 & (3.8) & 10,150 & $(96.2)$ & \\
\hline \multicolumn{8}{|l|}{ Charlson Comorbidity Index } \\
\hline 0 & 10,232 & $(55.0)$ & 302 & (3.0) & 9930 & $(97.1)$ & $<0.0001$ \\
\hline 1 & 3080 & (16.5) & 163 & (5.3) & 2917 & (94.7) & \\
\hline 2 & 2573 & (13.8) & 169 & (6.6) & 2404 & (93.4) & \\
\hline $3+$ & 2736 & $(14.7)$ & 279 & $(10.2)$ & 2457 & (89.8) & \\
\hline \multicolumn{8}{|l|}{ Length of stay } \\
\hline$\leq 7$ days & 7946 & $(42.7)$ & 536 & (6.8) & 7410 & (93.3) & $<0.0001$ \\
\hline$\overline{7}<$ days $\leq 14$ & 3540 & (19.0) & 157 & (4.4) & 3383 & (95.6) & \\
\hline $14<$ days $\leq 21$ & 1722 & (9.3) & 39 & (2.3) & 1683 & (97.7) & \\
\hline $21<$ days & 5413 & $(29.1)$ & 181 & (3.3) & 5232 & $(96.7)$ & \\
\hline \multicolumn{8}{|l|}{ Treatment } \\
\hline Operation & 3240 & $(17.4)$ & 471 & (14.5) & 2769 & (85.5) & $<0.0001$ \\
\hline Other & 15,381 & (82.6) & 442 & $(2.9)$ & 14,939 & (97.1) & \\
\hline \multicolumn{8}{|l|}{ No. of hospital beds } \\
\hline $100-299$ & 8362 & (44.9) & 149 & (1.8) & 8213 & (98.2) & $<0.0001$ \\
\hline $300-499$ & 2982 & (16.0) & 163 & (5.5) & 2819 & (94.5) & \\
\hline $500-999$ & 5996 & (32.2) & 507 & (8.5) & 5489 & (91.5) & \\
\hline $1000-$ & 1281 & (6.9) & 94 & (7.3) & 1187 & (92.7) & \\
\hline \multicolumn{8}{|l|}{ Intention of injury } \\
\hline Intentional & 1042 & $(5.6)$ & 35 & (3.4) & 1007 & (96.6) & 0.0175 \\
\hline Unintentional & 17,579 & (94.4) & 878 & (5.0) & 16,701 & (95.0) & \\
\hline \multicolumn{8}{|l|}{ Main injury location } \\
\hline Head & 18,469 & (99.2) & 881 & (4.8) & 17,588 & (95.2) & $<0.0001$ \\
\hline Neck & 46 & $(0.3)$ & 10 & $(21.7)$ & 36 & (78.3) & \\
\hline Others & 106 & $(0.6)$ & 22 & (20.8) & 84 & (79.3) & \\
\hline \multicolumn{8}{|l|}{ Type of severe injury } \\
\hline Single-injury & 15,586 & (83.7) & 484 & $(3.1)$ & 15,102 & (96.9) & $<0.0001$ \\
\hline Multiple-injury & 3035 & (16.3) & 429 & $(14.1)$ & 2606 & (85.9) & \\
\hline \multicolumn{8}{|l|}{ Year } \\
\hline 2005 & 2612 & $(14.0)$ & 120 & (4.6) & 2492 & (95.4) & 0.9196 \\
\hline 2006 & 1949 & (10.5) & 99 & (5.1) & 1850 & (94.9) & \\
\hline 2007 & 1988 & $(10.7)$ & 94 & (1.7) & 1894 & (98.3) & \\
\hline 2008 & 2394 & (12.9) & 118 & (4.9) & 2276 & (95.1) & \\
\hline 2009 & 2284 & (12.3) & 106 & $(4.6)$ & 2178 & (95.4) & \\
\hline 2010 & 2363 & (12.7) & 123 & $(5.2)$ & 2240 & (94.8) & \\
\hline 2011 & 2505 & (13.5) & 119 & (1.8) & 2386 & (98.3) & \\
\hline 2012 & 2526 & (13.6) & 134 & (5.3) & 2392 & $(94.7)$ & \\
\hline Regional characteristics & & & & & & & \\
\hline No. of EDs per $1,000,000$ people & 10.2 & \pm 5.4 & 9.1 & \pm 4.5 & 10.3 & \pm 5.5 & $<0.0001$ \\
\hline No. of ambulances per 100,000 people & 16.4 & \pm 9.5 & 15.3 & \pm 8.5 & 16.4 & \pm 9.5 & $<0.0001$ \\
\hline No. of RNs per ED & 14.0 & \pm 5.0 & 14.8 & \pm 5.0 & 14.0 & \pm 4.9 & $<0.0001$ \\
\hline $\begin{array}{l}\text { No. of emergency medicine specialists } \\
\text { per ED }\end{array}$ & 2.1 & \pm 1.0 & 2.2 & \pm 0.9 & 2.1 & \pm 1.0 & $<0.0001$ \\
\hline No. of total specialists per ED & 2.8 & \pm 0.8 & 3.0 & \pm 0.8 & 2.8 & \pm 0.8 & $<0.0001$ \\
\hline Rate of $<1 \mathrm{hr}$ to arrive at ED after onset & 0.4 & \pm 0.1 & 0.4 & \pm 0.1 & 0.4 & \pm 0.1 & 0.1059 \\
\hline GRDP (million won) & 26.9 & \pm 8.5 & 26.6 & \pm 8.6 & 27.0 & \pm 8.4 & 0.2432 \\
\hline Population density (1000 people/km²) & 3449.2 & \pm 5534.5 & 4111.8 & \pm 5888.6 & 3415.1 & \pm 5513.7 & 0.0005 \\
\hline Total & 18,621 & $(100.0)$ & 913 & $(4.9)$ & 17,708 & $(95.1)$ & $<0.0001$ \\
\hline
\end{tabular}




\begin{tabular}{|c|c|c|c|c|}
\hline \multirow[b]{2}{*}{ Variables } & \multicolumn{4}{|c|}{ Death during hospitalization } \\
\hline & Adjusted OR & & $\% \mathrm{Cl}$ & $p$-value \\
\hline \multicolumn{5}{|l|}{ Individual characteristics } \\
\hline \multicolumn{5}{|l|}{ Sex } \\
\hline Male & 1.00 & & & \\
\hline Female & 0.63 & 0.53 & 0.74 & $<0.0001$ \\
\hline Age & 1.02 & 1.01 & 1.02 & 0.0002 \\
\hline \multicolumn{5}{|l|}{ Type of insurance coverage } \\
\hline $\mathrm{NHI}$ & 1.00 & & & \\
\hline Medical-aid & 1.61 & 1.18 & 2.20 & 0.0029 \\
\hline Vehicle insurance & 1.43 & 1.20 & 1.69 & $<0.0001$ \\
\hline \multicolumn{5}{|l|}{ Charlson Comorbidity Index } \\
\hline 0 & 1.00 & & & \\
\hline 1 & 1.23 & 0.94 & 1.62 & 0.1301 \\
\hline 2 & 1.28 & 0.92 & 1.78 & 0.1365 \\
\hline $3+$ & 1.81 & 1.23 & 2.66 & 0.0026 \\
\hline \multicolumn{5}{|l|}{ Length of stay } \\
\hline$\leq 7$ days & 1.00 & & & \\
\hline$\overline{7}<$ days $\leq 14$ & 0.31 & 0.25 & 0.38 & $<0.0001$ \\
\hline $14<$ days $\leq 21$ & 0.12 & 0.08 & 0.17 & $<0.0001$ \\
\hline $21<$ days & 0.08 & 0.06 & 0.10 & $<0.0001$ \\
\hline \multicolumn{5}{|l|}{ Treatment } \\
\hline Operation & 1.00 & & & \\
\hline Other & 0.14 & 0.11 & 0.17 & $<0.0001$ \\
\hline \multicolumn{5}{|l|}{ No. of hospital beds } \\
\hline $100-299$ & 1.00 & & & \\
\hline $300-499$ & 2.77 & 2.14 & 3.59 & $<0.0001$ \\
\hline $500-999$ & 3.03 & 2.39 & 3.83 & $<0.0001$ \\
\hline $1000-$ & 2.15 & 1.56 & 2.97 & $<0.0001$ \\
\hline \multicolumn{5}{|l|}{ Intention of injury } \\
\hline Intentional & 1.00 & & & \\
\hline Unintentional & 1.16 & 0.80 & 1.67 & 0.4353 \\
\hline \multicolumn{5}{|l|}{ Main injury location } \\
\hline Head & 1.00 & & & \\
\hline Neck & 6.22 & 2.38 & 16.24 & 0.0002 \\
\hline Others & 3.67 & 2.07 & 6.51 & $<0.0001$ \\
\hline \multicolumn{5}{|l|}{ Type of severe injury } \\
\hline Single-injury & 1.00 & & & \\
\hline Multiple-injury & 4.68 & 3.93 & 5.57 & $<0.0001$ \\
\hline \multicolumn{5}{|l|}{ Year } \\
\hline 2005 & 1.00 & & & \\
\hline 2006 & 1.17 & 0.86 & 1.59 & 0.3156 \\
\hline 2007 & 0.98 & 0.72 & 1.34 & 0.9070 \\
\hline 2008 & 1.13 & 0.84 & 1.51 & 0.4220 \\
\hline 2009 & 1.08 & 0.79 & 1.46 & 0.6296 \\
\hline 2010 & 1.37 & 1.02 & 1.84 & 0.0336 \\
\hline 2011 & 1.42 & 1.06 & 1.91 & 0.0177 \\
\hline 2012 & 1.22 & 0.92 & 1.64 & 0.1734 \\
\hline \multicolumn{5}{|l|}{ Regional characteristics } \\
\hline No. of EDs per $1,000,000$ people & 0.94 & 0.91 & 0.98 & 0.0009 \\
\hline No. of ambulances per 100,000 people & 0.99 & 0.98 & 0.99 & 0.0485 \\
\hline No. of RNs per ED & 0.88 & 0.83 & 0.94 & $<0.0001$ \\
\hline No. of emergency medicine specialists per ED & 1.13 & 0.84 & 1.53 & 0.4110 \\
\hline No. of total specialists per ED & 1.26 & 0.91 & 1.75 & 0.1699 \\
\hline Rate of $<1 \mathrm{hr}$ to arrive at ED after onset & 0.10 & 0.02 & 0.62 & 0.0135 \\
\hline GRDP (million won) & 1.00 & 0.99 & 1.01 & 0.7188 \\
\hline Population density (1000 people/km²) & 1.04 & 1.00 & 1.07 & 0.0395 \\
\hline
\end{tabular}




\begin{tabular}{|c|c|c|c|c|c|c|c|c|}
\hline \multirow[b]{3}{*}{ Variables } & \multicolumn{7}{|c|}{ Type of severe injury } & \\
\hline & \multicolumn{4}{|c|}{ Single-injury } & \multicolumn{4}{|c|}{ Multiple-injury } \\
\hline & Adjusted OR & & $\mathrm{Cl}$ & $p$-value & Adjusted OR & & $\% \mathrm{Cl}$ & $p$-value \\
\hline \multicolumn{9}{|l|}{ Regional characteristics } \\
\hline No. of EDs per $1,000,000$ people & 0.91 & 0.87 & 0.96 & 0.0001 & 0.97 & 0.92 & 1.04 & 0.4066 \\
\hline No. of ambulances per 100,000 people & 1.00 & 0.98 & 1.01 & 0.5074 & 0.99 & 0.97 & 1.01 & 0.3587 \\
\hline No. of RNs per ED & 0.79 & 0.73 & 0.86 & $<0.0001$ & 1.08 & 0.97 & 1.20 & 0.1531 \\
\hline No. of emergency medicine specialists per ED & 1.16 & 0.77 & 1.75 & 0.4832 & 0.97 & 0.62 & 1.50 & 0.8760 \\
\hline No. of total specialists per ED & 1.58 & 0.99 & 2.51 & 0.0536 & 0.81 & 0.50 & 1.31 & 0.3867 \\
\hline Rate of $<1 \mathrm{hr}$ to arrive at the ED after onset & 0.01 & 0.00 & 0.07 & $<0.0001$ & 15.33 & 0.56 & 420.65 & 0.1063 \\
\hline GRDP (million won) & 0.99 & 0.98 & 1.01 & 0.5020 & 1.02 & 1.00 & 1.04 & 0.0966 \\
\hline Population density (1000 people/km²) & 1.07 & 1.02 & 1.12 & 0.0060 & 0.97 & 0.92 & 1.03 & 0.3097 \\
\hline
\end{tabular}

This difference was likely due to this study's lack of consideration of the details of the ED in each hospital, such as the number of patients for each doctor and the severity of the patients who visited the ED. ${ }^{25,26}$ Nonetheless, the results of the subgroup analyses according to the type of severe injury demonstrated that only singleinjury patients presented an inverse correlation between emergency medical resources and mortality. Most patients in this study were single-injury patients, which may explain the reason that South Korea has a preventable death rate of injured patients that is 3-4 times higher than that of other developed countries. If an effective counterplan for single-injury patients to receive proper treatment in time is provided, the preventable death rate of injured patients is likely to sufficiently decrease.

Timely transport and medical care within 1 hour is well known to increase trauma victims' survival chances. However, an effective trauma care system in South Korea has not been firmly established. Currently, while regional emergency medical centres cover most patients with severe trauma, they are overcrowded and lack adequate personnel and hospital beds. ${ }^{27,28}$ These problems hinder the timely treatment of severely injured patients and the effective operation of emergency medical resources, and they also lower the quality of service for inpatients. $^{29-31}$

Another problem is that most trauma patients are transported to the nearest local hospital as opposed to a trauma centre. ${ }^{24}$ Many local emergency medical institutions do not meet even the basic personnel requirements and do not have physician staffing at all times. As a result, patients fail to receive critical trauma care during this first hour. To respond to this need, the Republic of Korea government established a plan in 2011 to design and operate 17 regional trauma centres around the country, and this plan is in the process of being implemented. However, challenging circumstances, including the economic pressures under which South Korea's complicated medical environment operates, have crippled the plan's successful progress. As a result, only two regional trauma centres have opened nationwide as of July $2014 .^{24}$

Therefore, the government's policy to double the number of regional emergency medical centres and improve the criteria of facilities, equipment, and personnel seems to have been only partially effective. A more effective way to improve the emergency medical system may be to not only increase the quantity of emergency medical resources, but also focus on increasing their quality. South Korea has offered few financial and non-financial rewards for providing quality emergency medical care, and this lack of incentive likely prevents improvements to the quality of local emergency medical care centres and local emergency medical institutions. ${ }^{32}$ Therefore, the nation needs to provide support to meet the criteria of personnel, facilities, and equipment for each emergency medical centre and encourage centres to provide a superior quality of emergency medical services by adopting a compensation system for emergency medical care. 
This study had several strengths compared to previous studies. First, the survey data were collected from hospitals in each region, representing regional characteristics in South Korea. Additionally, the data examined in our study recognized the hierarchical nature of the institutions and captured the diversity of both individual and regional characteristics as much as possible. Such data are especially helpful in establishing evidence-based health policies.

However, this study also had several limitations related to limited data and methodological issues. First, these data did not include individual characteristics, such as socioeconomic status and time of arrival at the hospital after injury. To overcome this limitation, we included regional indicators, such as GRDP and taking less than 1 hour to arrive to the ED after onset, for each region in the study. In addition, we only considered death during hospitalization due to data limitations; specifically, we were unable to consider death on the scene, death on arrival, death in the ED, death after leaving the hospital, and transfer to another hospital's ED. However, we attempted to control the regional variables, such as taking less than 1 hour to arrive at the ED after onset, to minimize the data limitations. Additional studies that include data regarding the patient's health conditions before hospitalization and after leaving the hospital are required. Moreover, this study showed several unexpected results, such as an association between the number of specialists and mortality, that were likely due to our lack of consideration of the details of the ED in each hospital, including the number of patients for each doctor and the severity of the patients who visited the ED. Finally, this study may have had a validity issue, because severely injured patients were selected by diagnosis. Severe injuries defined by the principal diagnosis comprised mostly head injuries, and patients with multiple severe injuries were defined as those who were diagnosed with more than two severe injuries. Most of the patients had single severe injuries, because there were not many cases of multiple severe injuries. However, as we used the principal diagnosis of the severely injured patients that was proposed in the report from the central emergency medical centre, our study results were likely not greatly different from reality.

Despite these limitations, our findings suggest that regional emergency medical resources decrease the risk of mortality during hospitalization in severely injured patients. The trauma system of South Korea is in its infancy. Trauma patient care needs a systematic approach. Health care policymakers and professionals should share the same mission and goals for the treatment of trauma to build a desirable trauma system. Our results will be important in the development of effective strategies for improving health care outcomes in South Korea.

\section{CONCLUSIONS}

Our findings suggest that regional emergency medical resources were associated with a lower risk of mortality during hospitalization in severely injured patients, providing valuable information for health care policymakers and professionals. Thus, health care policymakers need to consider the proper distribution of the emergency medical resources for each region and the function of EDs to provide superior quality of emergency medical services to patients.

Acknowledgements: The authors would like to thank Manjusha Sala, Associate Managing Editor of BioScience Writers, LLC, for reviewing and translating an earlier version of this article. We also wish to thank Jonas Robertson, Associate Managing Editor of Medical Research in Yonsei University, College of Medicine, for reviewing and translating the final version of this article.

Competing interests: None declared.

\section{SUPPLEMENTARY MATERIAL}

To view supplementary material for this article, please visit https://doi.org/10.1017/cem.2016.402

\section{REFERENCES}

1. Statistics Korea. All cause of mortality; 2014. Available at: http://www.kostat.go.kr/portal/korea/kor_nw/2/1/index. board? bmode $=$ read\&aSeq $=348539$.

2. Organisation for Economic Co-operation and Development. Health at a glance. OECD; 2013. Available at: https://www. oecd.org/els/health-systems/Health-at-a-Glance-2013.pdf.

3. Lee KH. Optimal trauma care system in Korea. 7 Korean Med Assoc 2013;56:748-50.

4. Esposito TJ, Sanddal TL, Reynolds SA, et al. Effect of a voluntary trauma system on preventable death and inappropriate care in a rural state. 7 Trauma Acute Care Surg 2003;54:663-70.

5. Park K, Lee JS, Kim Y, et al. The socioeconomic cost of injuries in South Korea. 7 Prev Med Public Health 2009;42:5-11.

6. Ministry of Health \& Welfare. Emergency Medical Service Act; 2014. Available at: http://www.law.go.kr/lsInfoP.do? lsiSeq $=162490 \& \mathrm{chrClsCd}=010203 \& u r l M o d e=e n g L s I n$ foR\&viewCls=engLsInfoR\#0000. 
7. Statistics Korea. Emergency medical status; 2013. Available at: media.nemc.or.kr/file/download_file.do? fileitemno $=289$.

8. Korean Institute of Hospital Management. Problems and improvements of domestic emergency medical system; 2013. Available at: http://www.kihm.re.kr/kxe/?mod$\mathrm{ule}=$ file $\&$ act $=$ procFileDownload $\&$ file_srl $=31589 \& \mathrm{sid}=$ $1 \mathrm{ca} 149635780 \mathrm{bb} 15 \mathrm{~b} 40016 \mathrm{e} 503669 \mathrm{bbb}$.

9. Rhee H, Kim MS, Oh J, et al. Analysis of factors that will ensure effective health care delivery system. Korea Society Digital Policy Manag 2012;10:303-10.

10. Guttmann A, Schull MJ, Vermeulen MJ, et al. Association between waiting times and short term mortality and hospital admission after departure from emergency department: population based cohort study from Ontario, Canada. BMf 2011;342:d2983.

11. Ministry of Health \& Welfare. Emergency Medical Service Act; 2015. Available at: http://www.law.go.kr/lsInfoP.do?lsiSeq $=167720 \& \operatorname{chrClsCd}=010203 \&$ urlMode $=$ engLsInfo R\&viewCls=engLsInfoR\#0000.

12. Chang DC, Eastman B, Talamini MA, et al. Density of surgeons is significantly associated with reduced risk of deaths from motor vehicle crashes in US counties. $7 \mathrm{Am}$ Coll Surg 2011;212:862-6.

13. Desai A, Bekelis $\mathrm{K}$, Zhao $W$, et al. Increased population density of neurosurgeons associated with decreased risk of death from motor vehicle accidents in the United States. 7 Neurosurg 2012;117:599-603.

14. Metcalfe D, Bouamra O, Parsons N, et al. Effect of regional trauma centralization on volume, injury severity and outcomes of injured patients admitted to trauma centres. Br 7 Surg 2014;101:959-64.

15. Liberman M, Mulder DS, Jurkovich GJ, et al. The association between trauma system and trauma center components and outcome in a mature regionalized trauma system. Surgery 2005;137:647-58.

16. Gabbe BJ, Biostat GD, Simpson PM, et al. Improved functional outcomes for major trauma patients in a regionalized, inclusive trauma system. Ann Surg 2012;255:1009-15.

17. Celso B, Tepas J, Langland-Orban B, et al. A systematic review and meta-analysis comparing outcome of severely injured patients treated in trauma centers following the establishment of trauma systems. 7 Trauma Acute Care Surg 2006;60:371-8.

18. Kim MH, Subramanian S, Kawachi I, et al. Association between childhood fatal injuries and socioeconomic position at individual and area levels: a multilevel study. 7 Epidemiol Community Health 2007;61:135-40.
19. Choi YE, Lee KS. Multilevel analysis on factors influencing death and transfer in inpatient with severe injury. Health Policy Manag 2013;23:233-43.

20. Korea Health Industry Development Institute. Analysis on emergency medical service areas; 2010. Available at: https:// www.khidi.or.kr/fileDownload?titleId=100535\&fileId=1.

21. National Emergency Medical Center. Emergency medical statistics; 2012. Available at: http://www.e-gen.or.kr/ nemc/statistics_annual_report.do.

22. Statistics Korea. Korean statistical information service; 2011. Available at: http://kosis.kr/statisticsList/statisticsList_01List.jsp.

23. Eastman AB, MacKenzie EJ, Nathens AB. Sustaining a coordinated, regional approach to trauma and emergency care is critical to patient health care needs. Health Affairs 2013;32:2091-8.

24. Kim J, Heo Y, Lee JC, et al. Effective transport for trauma patients under current circumstances in Korea: a single institution analysis of treatment outcomes for trauma patients transported via the domestic 119 Service. 7 Korean Med Sci 2015;30:336-42.

25. West MA, Guthrie JP, Dawson JF, et al. Reducing patient mortality in hospitals: the role of human resource management. F Organ Behav 2006;27:983-1002.

26. Bamberger PA, Biron M, Meshoulam I. Human resource strategy: formulation, implementation, and impact. Routledge, London, 2014.

27. Ministry of Health \& Welfare. Emergency medical evaluation, 2011; 2012. Available at: http://www.mohw.go.kr/ front_new/al/sal0301vw.jsp?PAR_MENU_ID=04\&MENU_ID $=0403 \&$ page $=1 \&$ CONT_SEQ $=275377 \&$ SEAR CHKEY=TITLE \&SEARCHVALUE $=\%$ C0\% C0\% B 1 $\% \mathrm{DE} \% \mathrm{C} 0 \% \mathrm{C} 7 \% \mathrm{~B} 7 \% \mathrm{E} 1 \% \mathrm{~B} 1 \% \mathrm{E} 2 \% \mathrm{~B} 0 \% \mathrm{FC}$.

28. Youn YK. Regionalization strategy of the emergency medical service system. 7 Korea Med Assoc 2012;55:606-8.

29. Hoot NR, Aronsky D. Systematic review of emergency department crowding: causes, effects, and solutions. Ann Emerg Med 2008;52:126-36.

30. Sun BC, Hsia RY, Weiss RE, et al. Effect of emergency department crowding on outcomes of admitted patients. Ann Emerg Med 2013;61:605-11.

31. Olshaker JS. Managing emergency department overcrowding. Emerg Med Clin N Am 2009;27:593-603.

32. Kim Y. Future agenda for emergency medical service in Korea: from silos to systems. Korea Med Assoc 2015;58:776-9. 